\title{
INVOLVEMENT OF ATTENTION AND WORKING MEMORY OF CHILDREN WITH ADHD IN SCHOOL-AGE
}

\author{
Bibiana Regueiro, Tania Vieites, Iris Estévez, Carolina Rodríguez-Llorente, \\ Antonio Valle, \& Susana Rodríguez \\ Department of Psychology, University of A Coruña (Spain)
}

\begin{abstract}
This investigation analyzes the difficulties in attention and memory of children with Attention Deficit Disorder and Hyperactivity (ADHD) between eight and twelve years old (attending fourth, fifth and sixth grade of primary school) compared with a control group of the same age $(n=80)$, by applying three standardized tests: the test of perception of differences or test face, Children's Color Trails Test (CCTT) and test digit by Wechsler Intelligence Scale. These tests analyze selective attention, sustained attention, alternating attention, short term memory and working memory, respectively. The results show significant differences between the control group (group without ADHD) and ADHD group in all evaluated cognitive processes. In addition, differences in the correlations of these functions in both groups, checking that there may be a close relationship between attention deficit and implementation of other cognitive processes.
\end{abstract}

Keywords: Memory, attention, cognitive processes, $A D H D$, primary education.

\section{Introduction}

The Disorder Attention Deficit Hyperactivity disorder (ADHD), which is defined as a neurodevelopment disorder that is characterized by symptoms of inattention, hyperactivity and impulsivity that are inconsistent with developmental level and that impact negatively on social activities and academic (DSM-5, 2013). This symptomatology affects in different degrees and with different combinations that, in many cases, are supplemented with comorbid disorders, such as conduct disorders and/or learning difficulties.

According to the APA (2013), the ratio boys/girls is 4 to 1 in the general population and from 9 to 1 in the clinical population, differences that tend to disappear in adolescence. Children tend to show more severe symptoms than girls, especially hyperactivity, whereas girls are attention deficits (Barkley, 2006a; Biederman et al., 2004 as cited in Lavigne and Romero, 2010). The DSM-5 (APA, 2013) provides prevalence rates between $3 \%$ and $7 \%$ in the child population between 6 and 12 years, but the highest prevalence is found in the age range of 6-9 years. For this reason, its study is fundamental to the educational development of the people affected.

On the other hand, there are different types of ADHD, that is to say, that such a disorder encompasses different modalities, or have different manifestations. The DSM-5 defines the following three; predominantly inattentive, predominantly hyperactive-impulsive type and presentation combined. All subtypes are recognized under the label of attention deficit disorder with hyperactivity (ADHD), although present only attention deficit or predominant subtype hyperactive.

If we focus on the different presentations of ADHD, subtype is the most common inattentive even though the combined is the most diagnosed. In a study of meta-analysis of Willcutt (2012), it was found that the presentation inattentive is up to two times more frequent than the combined in-school age, although may seem paradoxical results is because those affected by the presentation of the combined flock prior to the consultation, and therefore it is diagnosed with greater frequency.

ADHD is understood as a neurodevelopment disorder that affects level maturational brain and to the knowledge areas of the brain. Shows that these alterations in certain areas of the brain translate into cognitive processes that are dysfunctional and result in behavioral responses different. On the one hand, the attention processes are essential in the executive functions of the school. For example, working memory refers to the ability to hold and manipulate for a short period of time the information needed to guide a certain behavior (Enseñat, 2015). School children with ADHD have difficulties in the ability to hold in mind the information necessary to guide the actions, remembering to do things in the near future, difficulty to memorize and follow instructions, forget a information while working in another and, also, difficult to 
manipulate and transform the information stored at the service of guiding behavior toward a goal. That is to say, as stated by Díaz et al. (2013) the symptoms present in ADHD cause some functional impairment in the student body that presents it. The research carried out in the Autonomous University of Barcelona for Garcia, Estévez, \& Junqué (2001), determined that students with ADHD have damaged your skills hygiene, that is to say, they have difficulties in working memory and in short-term memory, in particular, the immediate memory is more damaged.

This study seeks to answer the following question: do students with ADHD aged 8 to 12 years show largest deficits in the different types of attention and working memory that the children without ADHD of the same age? From this question it sets out two general objectives: to study selective attention, sustained and alternating, short-term memory and working memory in children with ADHD and to test whether there are significant differences between the groups.

\section{Methods}

The participants are students of educational institutions of the Autonomous Community of Madrid and the province of A Coruña, all of them in Spain. The sample was chosen intentionally according to the availability of facilities, the diagnosis of the school and the age range of the study. The final sample was composed by 80 school children between 8 and 12 years, 40 school children with ADHD and 40 school children without ADHD, all enrolled fourth, fifth, and sixth of Primary Education. In the group with ADHD is to affirm the prevalence of the male gender with a total of 29 school children $(72,5 \%)$ and 11 girls $(27,5 \%)$ compared to the control group that is homogeneous with a total of 20 school children (50\%) and 20 school girls $(50 \%)$. The mean age of the sample is 10.4 years in the group with ADHD and 10.3 years in the group without ADHD. The instruments used have been the following:

Test of Faces Revised (Thurstone \& Yela, 2001). This revised version of the test includes scales from a sample at the national level that exceeds twelve thousand school children. The coefficient of reliability is a statistic that indicates the precision or stability of the results. Notes the amount in which the measures of the test are error-free casual. Thus, a reliability index of 0.90 means that, in the sample and the conditions used, 90 per 100 of the variance of the test should be the true measure and only 10 per 100 to random errors.

Children's Color Trails Test (CCTT) (Llorente, Williams, Satz, \& DElia, 2003). CCTT is a test that consists of two parts. The first assesses sustained attention while the second evaluates the care alternate. In other words, the portion A is primarily a test of visual attention that involve follow-up perceptive, and a simple sequencing, while the part B, due to the sequence alternates evaluates more directly the frontal systems of operation.

Test of Digits in the Scale of Intelligence WISC-IV (Wechsler, 2005). The digit test assesses working memory, ability to retain it temporarily in the memory certain information, working or trading with it and generate a result. It is also a measure of the short-term memory and attention, assessing the capacity of the school to retain several elements that have no logical relationship to each other. The Digit test presents an adequate internal consistency, good test-retest reliability, and adequate construct validity.

\section{Discussion and conclusions}

The results show that children with ADHD show a lower performance that the students of the control group in reaction time, responding more slowly, the results obtained through the test CCTT, which assesses sustained attention and attention alternate. These results show that school children with ADHD have a greater attention deficit, as indicated by the current literature and the diagnostic criteria of the disorder. In addition, in the assessment of sustained attention have been found notable differences between the two groups, according to Barkley (1997), relate it clearly with a dysfunction attention.

In the second place, the results allow to conclude that the performance of children with ADHD in the digit test, especially in digits in reverse order, is lower than that of the students in the control group. These data are consistent with the existing literature (Hale et al., 2002), this test measures the working memory and short-term memory as in this study and in other studies (García et al., 2001), studies whose results have revealed a lower performance of school children with ADHD compared to children who do not have the disorder.

In the third place, Narbona and Crespo-Eguilaz (2005) highlights that the sustained attention and working memory operate synchronously to give continuity and coherence to the mental activity and human behavior. In our study, the association between sustained attention and working memory in the group with ADHD is very high, corroborating the claim.

Therefore, from the results obtained it can be concluded that children with ADHD have lower performance than children in the control group on tests assessing attention, and to a lesser extent, show 
deficits in the cognitive processes assessed by the digit test. Showing that for students with ADHD is more difficult to focus and maintain attention to perform tasks that require the involvement of working memory. To conclude, it is considered necessary to emphasize the importance of further research on the disorder in order to improve the diagnosis and treatment of children who have ADHD. In addition to cope with the limitations of this study, as for example; to expand the sample to study, to take into account the subtype of ADHD (combined, inattentive and hyperactive-impulsive) or the fact that the groups are not equivalent in terms of gender.

\section{Acknowledgements}

This work was developed with the financing of the research 879 projects EDU2013-44062-P (MINECO), EDU2017-82984-P 880 (MEIC), and Government of the Principality of Asturias, 881 Spain. European Regional Development Fund (Research Groups 882 Program 2018-2020 FC-GRUPIN-IDI/2018/000199).

\section{References}

American Psychiatric Association., Kupfer, D.J., Regier, D.A., Arango López, C., Ayuso-Materos, J. L., Vieta Pascual, E., \& Bagney Lifante, A. (2013). DSM-5: Manual de Diagnóstico y estadístico de los trastornos mentales ( $5^{a}$ ed). Madrid: Editorial Médica Panamericana.

Barkley, R.A. (1997). Behavioral inhibition, sustained attention and executive functions: Constructing a unifying theory of ADHD. Psychological Bulletin, 121, 65-94.

Enseñat, A. (2015). Neuropsicología pediátrica. Madrid: Síntesis.

García, C., Estévez, A., \& Junqué, C. (2001). Perfil de memoria en el trastorno por déficit de atención con hiperactividad. Anuario de Psicología, 32(4), 35-46.

Hale, J. B., Hoeppner, J. B., \& Fiorello, C.A. (2002). Analyzing digit span components for assessment of attention processes. Journal of Psychoeducational Assessment, 20,128-143.

Lavigne, R. \& Romero, J. F. (2010). El TDAH. Madrid: Pirámide.

Llorente, A. M., Williams, J., Satz, P., \& D’Elia, L. F. (2003). Children's Color Trails Test professional manual. Lutz, FL: Psychological Assessment resources.

Narbona, J. \&, Crespo-Eguilaz, N. (2005). Trastornos de memoria y de atención en disfunciones cerebrales del niño. Revista de Neurología, 40, 33-36.

Thurstone, L. L., \& Yela, M. (2012). Test de Percepción de Diferencias Revisado (CARAS-R). Madrid: TEA.

Wechsler, D. (2005). Escala de Inteligencia Wechsler para Niños IV (WISC-IV). Madrid: TEA.

Willcut, E. G. (2012). The Prevalence of DSM-IV Attention-Deficit/Hyperactivity Disorder: A Meta-Analytic Review. Neurotherapeutics, 9, 490-499. 